AUTHOR PRE-PRINT OF ARTICLE forthcoming in POLICY STUDIES

Citation

Tilbury, C. (forthcoming). Repositioning prevention in child protection using performance indicators. Policy

Studies. DOI: http://dx.doi.org/10.1080/01442872.2015.1110236

Author affiliation:

School of Human Services and Social Work, Griffith University, Australia.

Email: c.tilbury@griffith.edu.au

\title{
Repositioning prevention in child protection using performance indicators
}

\begin{abstract}
Performance indicators have both technical and value dimensions, capable of providing data for monitoring and reporting in addition to framing policy problems and their solutions. This paper considers the performance indicators proposed in a recent child protection inquiry in Australia that recommended "decreasing the numbers of children in the child protection system" as a primary policy objective. The paper examines the context in which the indicators were set, the values and theories they endorse, and how they position stakeholders. The analysis shows how the indicators communicate that child protection services should be only for the most serious cases of child maltreatment, and the reach of statutory services should be curtailed. Children who have been maltreated or who are at risk of harm from abuse or neglect should be diverted from the child protection system (positioned as bad) to the family support system (positioned as good), and at the same time from the state to the nongovernment sector. The shifting relations between government, service providers, and families signified by the indicators can be seen in a broader international context of tightening the boundaries around child protection and concurrently advancing concepts of compliance within family support.
\end{abstract}

Key words:

child protection, family support, performance measure, performance indicator, policy instrument

\begin{abstract}
Introduction
When viewed instrumentally, as a technical tool to retrospectively monitor policies and programs, performance measurement is grounded in a step-wise or rational view of policy: a policy problem exists, and knowledge (in the form of quantitative data) is obtained to aid policy choices. Indicators are neutral, following the logic of the problem, and developed in pursuit of the unproblematic values of efficiency and effectiveness. According to this approach, if properly conceptualised and constructed (or valid and reliable), performance indicators can illuminate the extent to which agencies or services are achieving goals and can provide accountability internally to the next level of management and externally to stakeholders. However, the requirement for clear, uncontested policy goals in the rational policy model does not recognise that stakeholders may have different aims and perspectives, and access to different forms of power in the policy process (Considine 1994). In social policy fields such as child protection, policy goals can be ambiguous, with multiple agendas pursued simultaneously. Various policy participants have different interpretations of central values (such as the best interests of the child), and the policy process is iterative and recursive rather than logical and orderly. Notions of best practice and good outcomes are contested. Therefore, if presented as technical or neutral, performance indicators de-politicise, presenting certain policy objectives as unproblematic, as if they do not serve particular interests or represent particular views of the world (Le Gales 2011).

An alternative approach is to conceptualise performance indicators as policy instruments that carry meanings and concepts, express policy frames, and organise relations between the state and the policy actors governed by them (Lascoumbes and Le Gales 2007; Le Gales 2011). Understanding performance indicators as policy instruments requires examination of their social as well as their technical capacities. The effectiveness of an indicator as a means to measure is not as important as other roles such as setting policy and structuring relations between policy participants. This approach opens up questions about who is "performing", the interpretations that are made of data, and how the indicators explain or theorise the relationships between government and nongovernment agencies, professionals, families, and other stakeholders in a policy field. It draws attention to the discursive function of indicators in communicating policy intent, shaping the way we think and talk about child protection, and defining notions of outcomes, effectiveness, and quality (Alastalo and Poso 2014; Tilbury 2004).
\end{abstract}




\section{Research on performance measurement in the child protection field}

Child protection systems comprise a set of social policies, legislation, organisational arrangements, and professional practices to respond to child abuse and neglect. Internationally, while there is significant variation between countries, three distinct orientations for child protection systems have been identified across developed European and Anglo-American countries: categorized as child protection; family support; or child focus (Gilbert, Parton and Skivenes 2011). The classification by Gilbert et al. considered the extent to which governments promoted child development, family support, or protection from parental abuse or neglect; whether policies were primarily targeted at social inequality or individual deviance; and how legalistic and adversarial services were. As such, they reflect distinct value orientations. Common trends were also noted over the past two decades. First, child protection was politically volatile, with intense media coverage of perceived failures in protecting individual children. Second, definitions of child abuse risks expanded, with more children coming to the attention of child protection authorities and more children in care. Third, managerial approaches to child protection increased, with new accountability and oversight mechanisms and more formal procedures and technologies for assessing and responding to children.

Performance measurement is an accountability mechanism now widely used in child protection. Much of the research on performance measurement in this field is in the rationalist mode, advancing the general view that performance measurement is a good thing, as long as the indicators are evidence-based, valid indicators of what they purport to measure and the data are available (Testa and Poertner 2010). Problems with government audits and performance improvement processes have been detailed. These include technical and empirical problems with the limitations of available administrative data, interpreting performance data without accounting for demographic variations between localities and states, contradictions between measures whereby improvement on one inevitably leads to decline on another, arbitrary standard-setting, and potential for gaming or manipulating data (Courtney, Needell and Wulczyn 2004). Two out-of-home care performance indicators have been the subject of considerable empirical scrutiny in Britain: placement stability and educational attainment. These are proxy child wellbeing indicators, measuring how frequently children are moved around from placement to placement, and how they are achieving in school compared to their peers. Research has examined whether these are the right goals to be aiming for, whether pursuing targets on these goals could undermine focus on individual children's needs, the difficulty of attribution due to the complex factors causing the problems, and the best measurement rules to apply for the indicators (Berridge 2012; Ward and Skuse 2001).

At a more conceptual level, there has been criticism that performance indicators are reductionist, too narrowly designed to measure the complexity of practice, and focused on quantity over quality, serving managerial interests rather than clients. For example, Gupta and Blewett (2007) argued that social work is about relationships with clients that are not amenable to measurement, and that many changes brought about in the lives of people receiving social work services are subtle and non-tangible, and cannot be represented as quantifiable outcomes. In existing child protection performance measurement regimes, there are few child and family outcome indicators, and a reliance on available output data (such as number of children and placements). Alastalo and Poso (2014) argued that as performance measures count and aggregate, they make their objects knowable and governable, and in doing so, simplify and mask the variation of social factors that lead to placement in out-of-home care. In representing certain policy objectives and "best practice" standards, indicators influence how the child protection system is conceptualised, how good practice is defined, and how funds are allocated. Therefore, with the focus of performance measurement on investigation and out-of-home care (the more intrusive parts of the system) the indicators represent a narrow and reactive view of child protection (Tilbury 2004). Notably missing are measures of family needs and services, and measures of children's social and emotional wellbeing.

A marked shift to the process of risk assessment as a central task of child protection can be seen as a manifestation of the 'risk society' in which reduced trust in government and expert knowledge has led to a societal concern to monitor, measure, explain, and contain risks (Munro 2010). There has been a considerable critique of performance measurement's role as a tool of risk management in child protection. According to Munro $(2004 ; 2010)$ performance measurement has encouraged the development of a culture of proceduralisation, blaming, deprofessionalisation, and computerisation of social work. She argued that performance audit processes in England changed over time from being a conversation about practice, to case file reviews that focused on completion of paperwork, thereby imposing an administrative burden that detracted from the amount of time social workers had to engage with children and families. Munro (2011) further argued indicators distorted practice by diverting the attention of the practitioner away from the needs of the individual client in favour of attaining output targets set by government.

This paper takes a critical and interpretive approach to examine the policy-setting functions of performance indicators. The empirical case examined is the indicators proposed by the recent Queensland Child Protection Commission of Inquiry (QCPCI). The Inquiry's recommendations provide the basis for current child protection policy directions in this State (QCPCI 2013). The analysis will consider: 
- The political context in which the performance indicators were set;

- The policy frames embedded in the indicators, how they represent the problem of child abuse, and the role of the child protection system; and

- The roles and responsibilities of government and nongovernment agencies, professionals, and families, and how these are demarcated in the indicators.

\section{The context for the Inquiry}

As a federation, in Australia child protection is the responsibility of state governments, each with their own legislation and approaches. The 2013 Queensland Child Protection Commission of Inquiry was established by a newly-elected conservative state government to fulfil an election promise. Unlike many other inquiries in child protection in both Australia and England, it was not prompted by a perceived crisis or critical event. The rationale for holding the Inquiry was increasing demands on the system: the fact that there had been no apparent improvements in the child protection system despite two previous major public inquiries and large injections of funds since 2000. The Inquiry was asked to examine a suite of problems that had arisen over the last decade, depicted as follows:

- the number of reports from hospitals, police, schools and community members concerned about possible child abuse or neglect tripled;

- the number of children in care doubled;

- statutory caseloads remained too high;

- the quality of out-of-home care placements had not improved, with less stability, less cultural matching, and inadequate support for young people upon leaving care; and

- the disparity of Aboriginal and Torres Strait Islander children in care worsened, with over-representation increasing from about $25 \%$ to $40 \%$ of children in care being Indigenous (when they are $5 \%$ of the total child population).

The terms of reference for the Inquiry stated that its recommendations should take account of a major audit taking place into the state budget. This led the Inquiry to "propose reforms that will not place a further strain on the state's finances" (QCPCI 2013, 1).

After taking evidence from government and nongovernment agencies, professionals, academics, carers, children and young people, and families, the Inquiry found that despite continual review and change, and significantly increased budgets over the past 15 years, a widespread public perception of systemic failure persisted. In order to achieve the child protection system's goals of ensuring the care and protection of children, the Inquiry made 121 recommendations to government in a report titled "Taking responsibility: a roadmap for Queensland child protection". There were three objectives for the roadmap: firstly, to reduce the number of children and young people in the child protection system; secondly, to revitalise frontline and family support services; and thirdly, to refocus oversight mechanisms (QCPCI 2013, 5). The performance indicators that were proposed for evaluating progress towards the first objective of reducing the number of children in the child protection system, which are the subject of this paper, are as follows:

- Performance indicator 1 (PI-1) - fewer children in out-of-home care;

- Performance indicator $2(\mathrm{PI}-2)$ - reduced rate of Aboriginal and Torres Strait Islander children in out-ofhome care;

- Performance indicator 3 (PI-3) - reduced number of reports and re-reports about suspected child abuse or neglect; and

- Performance indicator 4 (PI-4) - increased access to family support. (QCPCI 2013, 526-527)

\section{Defining the child protection system: The problem with diversion}

In general, child protection services in Australia are residual, characterised by a "child protection orientation" that aims to protect children from parental abuse or neglect within a legal and investigative framework, with a high threshold for state intervention (Gilbert et al. 2011). Despite policies to encourage supportive familybased responses to concerns about children, there are insufficient support services available (Lonne et al. 2009). There are very high rates of racial disparity, with Indigenous children being at least seven times more likely to be in care than non-Indigenous children, but overall not a high rate of children in out-of-home care by international standards (Tilbury \& Thoburn 2008). The number of reports of suspected child abuse and neglect has significantly increased markedly, with most reports not meeting the required threshold for action (QCPCl 2013, 85). Broadly, the Inquiry proposed to "divert" children and families from the coercive statutory interventions of investigation, court orders, and placement in out-of-home care, and increase access to voluntary family support services. This was based on the premise that helping families at early stages of problem development would improve outcomes for children and reduce costs later. This preventative turn is a 
well-rehearsed proposition in child protection in many countries, including Australia, Britain, and the Netherlands (Parton 2006; Van Nijnatten, Hopman, and Knijn 2014).

It might be argued that providing more in-home family support, reducing the number of children in care, and reducing the over-representation of Aboriginal and Torres Strait Islander children in care are worthy goals. They reinforce the principles of minimal intrusion into family life, that coercive state powers should not unduly interfere in how parents raise children, and that children have a right to family life. "Diverting families from the statutory system" comprised a whole chapter of the Inquiry report, concluding with 13 recommendations. But the concept of diversion that underpins the performance indicators is problematic. Diversion is a policy imported from the criminal justice system, based on redirecting or turning away from something bad to something good. It is not readily transferrable to child protection. The comparison is ill-made because diverting from juvenile detention or prison is entirely different to diverting from foster care or kinship care. Detention or prison is a punishment (albeit with a rehabilitation aim) imposed by the criminal justice system; placement is not a punishment. Drawing the analogy to child protection implies children who are vulnerable should preferably be diverted from the child protection system (bad) to the family support system (good). Thus, the indicators portray statutory child protection not just as investigation-focused, procedural and bureaucratic; but also as a dangerous or harmful system for children (van Nijnatten et al. 2014). Child protection intervention, whether an investigation of suspected abuse or neglect or placement in out-of-home care, is undertaken wholly for the benefit of the child, it is contradictory to regard it as something to be avoided. The roadmap's objective of reducing the number of children in the child protection system sits curiously at odds with the overall goal of the state to ensure the care and protection of children, as if the number of children who need protection is a financial drain on the government, rather than a vital service for vulnerable children.

Further, the premise of $\mathrm{PI}-1$ and $\mathrm{PI}-2$, that out-of-home care for children should be avoided, is not supported by research. Research has shown that delaying entry into care for some children may be costly in terms of longer exposure to maltreatment impairing the child's development, greater difficulty in meeting their needs, delayed permanence, and increased costs of placements (Ward and Skuse 2001). The problem with a "goal keeping" mode of child protection, in which out-of-home care is positioned as a last resort, is that a hands-off approach can lead to a worsening of family problems then result in unplanned, crisis placements, which are ultimately more resource intensive (Packman, Randall, and Jacques 1986).

Being in care is not uniformly bad for children. Certainly, research on educational attainment, health, and wellbeing, shows that children in care are worse off compared to their peers, and this adversely affects their adult outcomes (Barber and Delfabbro 2005; Berridge 2012). Yet this gap cannot all be attributed to the care system, it also relates to children's pre-care experiences that delay their development. There are detrimental effects of being in care, especially from placement instability and drift in unplanned care, as children's development is adversely affected by separation from family, cultural ties, and school friends (Bullock et al. 2006). The care system could do much more to address these losses, and the lack of belonging that many children experience. While findings about outcomes for children are based on the quality of care received in the past, outcomes for children in the future could be improved with better resourced and skilled out-of-home care. The research definitely provides grounds for advocating for improvements to the quality of foster care and other care system arrangements, but it does not provide a rationale for concluding that out-ofhome care should be avoided. Overall, research provides a nuanced picture of the efficacy of care, depending particularly on the age of children when they enter care, the type of placement provided, how long they stay, and the provision of after-care support (Bullock et al. 2006). And many children feel they are better off in care, feeling safe and cared for (Barber and Delfabbro 2005). Therefore, the diversion discourse misrepresents out-of-home care, conveying all the negatives of care, and few of the positives.

Child protection services are not inherently or necessarily legalistic and adversarial, they can be designed and operationalised with variable capacities to compel or empower. The performance objective of reducing the number of reports to the statutory agency $(\mathrm{PI}-3)$ reflects a long debate in child welfare about the proper balance between compulsory and supportive responses to child maltreatment. There are different perspectives, based partly on research and partly on changing public and professional norms about parenting and child care, regarding how much child abuse is caused by aberrant parental behaviour, or mediated by inequality and disadvantage. Many governments in recent years have been trying to ensure that the balance of resources is not weighted too heavily to compulsory interventions, which leaves insufficient resources for "early help" and preventative family support to assist socially disadvantaged families who have many needs (Thoburn 2013).

The Inquiry defined the reporting threshold (PI-3) for entry to the statutory system with reference to the "significant harm" threshold in the legislation, as services provided by the state when parents are unable or unwilling to protect a child. This definition provides no foundation for equating statutory services with coercive or compulsory services, to be avoided whenever possible. It is not clear why access to a service that is needed to protect a child should be restricted, or why intensive family support interventions are positioned 
as outside the statutory child protection system, when legislation expressly provides for family support responses to child abuse and neglect (Child Protection Act [QId] s5, s7). In reality, by statute and via funding arrangements, the child protection system comprises much more than the work that statutory child protection officers undertake with families regarding child abuse or neglect. In-home family support interventions are provided by statutory services through both supervision orders (granted by the court to give the state authority to issue directions to a parent and supervise a child's care while living at home with parents) and a type of family preservation response (called intervention with parental agreement). Further, the principles of respect for families and family participation in case planning are accepted as crucial to good child protection practice, whether statutory or not.

The performance indicators put forward by the Inquiry counter-pose child protection and family support, as if they are separate, for different risk categories. Out-of-home care is seen essentially as a child protection rather than as a family support service. It is mostly court-ordered, and consequently placement has a stigma attached to it for both children and parents. But in some countries (such as Denmark and Finland) out-of-home care is regarded as a positive support service for those who need it, and most children are placed on a voluntary basis with parental agreement. The Inquiry's recommendations were guided by the principle that the state is the last resort for protecting and caring for children (QCPCI 2014, 9). However, State intervention can come in many forms. State intervention is necessary to protect and care for children, supplementing what parents are able to provide, because parenting is one of many factors that influence children's wellbeing. The provision of education, health services, and public housing are forms of state intervention that make positive contributions to child wellbeing. So it is not the fact of state intervention that is the problem, it is the nature of it: that the state concentrates its child protection resources on coercive interventions with families. Consequently, State child protection services are seen as stigmatising, not supportive. The inference that nothing good comes of state intervention represents a retreat from statutory child protection work as quality social work with families to protect children.

The Inquiry proposed reducing the rate of Indigenous children in care as a measure of reform success (PI-2). Certainly, data on racial disproportionality and disparity can be used to assess the quality, equity, and effectiveness of services in protecting children and helping their families. However, with the disparity gap so wide, only modest gains can be achieved through concentrating on diversion. Different rates of entry to care can be explained by risk factors for child abuse and neglect not being evenly distributed throughout the population. If proportionately more Indigenous families experience hardships and live in disadvantaged communities, then more of their children may be at risk of abuse or neglect, and their families are more likely to be in need of culturally appropriate support and practical assistance. Attention is required to the social inequalities that lead to the patterned disparities observed in child welfare, as well as health and education systems (Bywaters, Brady, Sparks and Bos 2014). It is more critical, and just, to address the underlying causes of family problems for Indigenous people to improve family resources and living conditions, working collaboratively with Indigenous communities. Raising the threshold for entry to care, paradoxically, is likely to exacerbate over-representation, unless accompanied by policies and services that tackle the uneven distribution of poverty and other risk factors amongst children in Australia.

\section{The changing role of the nongovernment sector}

The performance indicators also signify a change in relations between government and nongovernment sectors, extending and making overt the responsibility of community-based family support agencies to monitor families. Over many decades, nongovernment agencies (especially those with religious and charitable roots) have played a role in delivering family support in Australia (Australian Institute of Health and Welfare 2001). Performance measurement is a tool to govern these organisations, providing a means of indirect control of service delivery to manage expenditure and action when government does not directly provide services (Salamon 2002). Contract arrangements require agencies to supply quantitative data about various elements of their functioning and meet performance targets. Here, performance measures are more than a technical mechanism to monitor performance; they structure relationships between government and nongovernment providers. The agencies perform to government specifications, and in doing so, their autonomy and flexibility are regulated. Casting statutory child protection in narrow terms has particular implications for preventative family support services, because a high threshold for access to child protection services has a flow-on effect to the threshold for obtaining family support.

The concept of prevention, with accompanying differentiation between primary, secondary and tertiary levels, is malleable, because prevention programs have a governance function. They define system boundaries or eligibility thresholds in a context where rationing services is important (Freeman 1999). While escalating numbers of reports of abuse and neglect led many states to invest in family support programs, the bulk of resources have been allocated to services targeting families with serious concerns about child maltreatment (Tomison 2002). There has been minimal expansion in broader, truly secondary-level family support for families experiencing moderate difficulty. Even so, intensive family support remains a small part of 
the child protection system, comprising only $17 \%$ of total State and Territory governments spending on child welfare in 2014 (SCRGSP 2015, Table 15A.1). The consequence of insufficient support services to meet the needs of families is higher thresholds, and more restrictive criteria for access to assistance.

Increased access to family support (PI-4) is to be achieved by priority being given to families reported to child protection. Family support becomes "semi-voluntary" and more conditional (Hayden and Jenkins 2014). This is another sign of the changing role of the state represented in the indicators, whereby the criteria for receipt of state services become more restrictive, and the community sector has an increased role. The performance indicators are not forming a new market, because family support has long been provided in the community sector, but it is remodelling the family support market, requiring it to provide different types of "products" or services. This reframes the idea of early intervention. While family support represents a move away from coercive services and provides for a more active role for families, the reframing also positions family support as having a stronger role in the governance of the family and the oversight of parenting.

Along with the changed role of the family support sector comes the necessity for more personal information about families to be exchanged between government and nongovernment agencies to facilitate referrals. Parton (2006) has observed that the current preventative shift is accompanied by development of new forms of information technology for recording and sharing information about families. These prevention programs involve large-scale screening and monitoring of risk, and exchange of information between designated professionals and between agencies. He argued that this approach to prevention makes the state more intrusive, more regulatory, with professionals (in children's services, police and health services) having increased responsibility and powers to intervene, and not only when a child has been abused or neglected, or there is risk of significant harm to a child. There is potential here for breaching privacy and undermining civil liberties, especially of people in "risk categories".

A further shift from government to nongovernment provision is embedded in the goal to decrease the number of reports about suspected child abuse or neglect to child protection authorities (PI-3) by implementing a community-based referral pathway. The objective of this indicator is contrary to at least three decades of public policy and legislation that has directed certain categories of professionals (teachers, doctors) to report suspected child abuse and neglect. Now government wants them to step back, because of the magnitude of the workload caused by the number of reports it receives. The Inquiry recommended that unless children were in immediate or serious danger, reporters should be encouraged to refer their concerns to a community agency rather than to the statutory agency, through the implementation of community-based intake (QCPCI 2014, recommendation 4.5). This inevitably leaves the indicators open to manipulation if the same total number of reports is made, because improvement on the indicator can be achieved by government redirecting reporters to an alternative (government-funded) community agency for screening and assessment. Moreover, having an alternative pathway for reporters does not in itself provide early intervention and support for families, which can only be achieved by having a sufficient number and range of services available. The nongovernment sector will have to manage the needs of families and the expectations of reporters within the funding allocations and contract arrangements that regulate their flexibility.

\section{Role of children and families}

Where is the voice of children, young people, and their families, how are they positioned as they are diverted from statutory services? There were no performance indicators proposed by the Inquiry to measure child and family views of services or whether services make a difference to them. The family support indicator (PI-4) does not refer to empowering or providing assistance to parents, it is about access to family support services. Funding is recommended for intensive family support services that give priority to "high-risk" families with multiple and complex needs in order to achieve diversion from statutory intervention (QCPCl 2014, recommendation 5.4). Following a referral expressing concern about the care of a child, such services seek the "agreement" of families to receive services. Accepting services is equated with caring for their children; the family has to accede to the intervention to show their willingness to improve their situation. The voluntary notion is further eroded as families understand if they do not "agree to participate" in services, child protection may step in. There is a compliance element here because as families are being governed, parents must perform for professionals. There is no allowance that services might be difficult to access, or not what families want, families must submit to services or face the prospect of more intrusive intervention. Parents are perceived as being not motivated, hostile, or resistant without due consideration to the power that professionals hold, or the fears that parents may have about child protection intervention. Thus, on the surface the preventative approach is empowering for families, but it also has a controlling element of identifying future risk and risky parents (Featherstone, White and Morris 2014; Van Nijnatten et al. 2014).

The categorical approach that sets service delivery options in opposition - statutory versus voluntary and child protection versus family support - implies there is no overlap between their goals and target clientele. That is, family support is for parents who access and participate in programs, who are not aggressive, difficult or uncooperative, and child protection is for parents who lack motivation to change, who 
won't "help themselves", who decline offers of help or are evasive. In reality, there is no clear distinction between the needs of families who receive a child protection service and families who receive a family support response. In selecting a response to concerns about children, much depends upon what services are available. And both these service types contain levels of voluntariness - for example, short-term placements or respite care are a type of family support service that parents may seek in a crisis. Linking access to family support ( $\mathrm{PI}-4)$ to the policy goal of diversion is consistent with the international trend of tightening the boundaries around child protection and concurrently advancing concepts of compliance within family support. It reinforces and intensifies the idea of family support as semi-voluntary, contrasting it with (coercive) child protection. It also casts family participation as entirely a decision for the parents, rather than as part of the skill repertoire of child protection practitioners and their capacity to engage with families, building rapport and trust, and using their professional power in a nuanced and productive manner.

The diversion goal and associated performance indicators contain an explanation for child maltreatment that is about individual parents "taking responsibility". This frames the care and protection of children in terms of the skills and resources of parents: if they access family support and repair their problems, they can avoid coercive child protection intervention. In doing so, it downplays the impact of social conditions, poverty, homelessness, racism, unemployment, disability, and ill-health. This policy direction of favouring individual over social responsibility is not confined to child protection; it is a characteristic of neoliberal welfare regimes (Gilbert et al. 2011). Yet holding people responsible for their behaviour is not contrary to recognising the environmental factors that can generate and sustain the problematic behaviour. Howe (1996) described this as a focus on surface over depth: rather than trying to theorise (that is, understand or explain), social workers focus on observable behaviour, less concerned with why clients behave as they do than with what they do. Social arrangements and social exclusion, the availability of jobs, housing, child care, family support, and school inclusiveness are downplayed while parental behaviours related to domestic violence, mental illness, or using alcohol or drugs are targeted as the crucial determinant of children's wellbeing. As valentine (2015) argues, whereas the concept of social exclusion describes the social processes that exclude, the concept of multi-problem families refers to the characteristics of families and signifies it is the families who need changing. Despite understanding that the causes of child abuse and neglect are both social and individual, all the prevention action is directed at individual behaviours or parenting practices, rather than social circumstances. A punitive approach is then taken towards parents, in the name of being child-centred (Featherstone et al. 2014). Therefore, the indicators define and identify good and bad parents according to their behaviours.

\section{The consequences - what is measured is valued}

There are technical problems with the indicators that arise from framing child protection in narrow terms, as a system from which children should be diverted. Firstly, they are indicators of service system outputs, attaching importance to quantity rather than quality. None of them are outcome or quality indicators, they do not measure improvements in children's safety or wellbeing, or enhancements in family functioning. Some are contradictory. For example, there is a fundamental contradiction in regarding out-of-home placement as undesirable, when it is done to protect the child. Perverse outcomes can result from avoiding placing a child who is not safe at home, or returning a child home prematurely to reduce numbers in care. Also, there is an inverse relationship between the rate of entry to care and placement quality. Lowering the rate of entry (by raising the threshold) so that only the most serious cases enter out-of-home care (PI-1), means that placement stability will decline, because it is harder to maintain placements in which children have emotional or behavioural problems. In fact, the rate of entries to care has been declining in Queensland for many years, as it is in the rest of Australia and many other countries (Australian Institute of Health and Welfare 2015, Gilbert et al. 2011). The reason there are more children in care is that duration in care has increased, so there are more children in care year-on-year (Tilbury \& Thoburn, 2008). This is a long-term trend that can only turn around if more reunification work is done. Increasing access to family support at the early stages is necessary, but not nearly sufficient, to reduce the number of children in care. Finally, there is no sound evidence base for the indicators. For example, there is no basis in research for setting a standard about the right rate of children in care (PI-1 and PI-2). Both "too high" and "too low" levels can be problematic: a low number of children being removed from their birth families can arise from either skilled help making the children safe, or from poor-quality risk assessments (Munro 2004; Tilbury \& Thoburn 2008).

\section{Conclusion}

Understanding the performance indicators set by the Queensland Child Protection Commission of Inquiry as a policy instrument facilitates an exploration of how they frame child protection policy and affect relations between government, service providers, and service users. The performance indicators communicate that child protection services should be only for the most serious cases of child maltreatment, statutory services are characterised as coercive, and the goal is to reduce the reach of statutory services. Children who are 
vulnerable should be diverted from the (narrowly defined) child protection system to the family support system and from the state to the community sector. In doing so, the performance indicators reposition prevention within the child protection system, moving family support from a voluntary service for families at the early stages of problem development, to a more conditional service. That is, families must cooperate with services and reduce their problem behaviours to avoid coercive intervention. This approach also repositions nongovernment family support agencies to become an agent of the smaller state, with referrals channelled to them from child protection and other government agencies. While these trends in service delivery have been perceptible over time, because the performance indicators are policy instruments that command resources, they elevate and make the policy objectives explicit, and intensify policy action towards them.

According to Power $(2004,778)$, the task of social science is to "open up the black box of performance measurement systems, to de-naturalize them and to recover the social and political work that has gone into their construction as instruments of control". This paper has considered the consequences of setting performance indicators that are directed towards reducing the number of children in the child protection system. In constructing child protection policy, it matters what type of family services are provided, to whom, by whom, and how statutory child protection and its practitioners are viewed. Performance information should not be treated as a straightforward or neutral measure of policy action, but interrogated to see what lies behind it, and the implications for government, the nongovernment sector, and families. The indicators discussed in this paper are consistent with an international trend of tightening the boundaries around child protection, and concurrently advancing concepts of compliance within family support. An alternative scenario is to conceptualise the child protection system as a positive service that helps vulnerable and multiply-disadvantaged families. Parents need services that genuinely help them with caring for their children and managing family stress, with sufficient intensity and levels of support, attending to both personal agency and structural inequalities that affect family life. Sometimes the services might be in-home, other times placement is needed. These services contain different levels of voluntariness and should not be positioned at opposite ends of a continuum.

\section{References}

Alastalo, M. and Poso, T. 2014. Number of children placed outside the home as an indicator: Social and moral implications of commensuration. Social Policy and Administration, 48, 7, 721-738.

Australian Institute of Health and Welfare 2015. Child Protection Australia 2013-2014. Canberra: Author.

Australian Institute of Health and Welfare 2001. Family support services in Australia 2000. Canberra: Author.

Barber, J. and Delfabbro, P. 2005. Children's adjustment to long-term foster care. Children and Youth Services Review, 27, 329-340.

Berridge, D. 2012. Educating young people in care: What have we learned? Children and Youth Services Review, 34, 1171-1175.

Bullock, R., Courtney, M.E., Parker, R., Sinclair, I., and Thoburn, J. 2006. Can the corporate state parent? Children and Youth Services Review, 28, 1344-1358.

Bywaters, P., Brady, G., Sparks, T. and Bos, E. 2014. Child welfare inequalities: new evidence, further questions. Child and Family Social Work, Advance online publication DOI: 10.1111/cfs.12154.

Considine, M. 1994. Public Policy: A Critical Approach. MacMillan, Melbourne.

Courtney, M.E., Needell, B. and Wulczyn, F. 2004. Unintended consequences of the push for accountability: The case of national child welfare performance standards. Children and Youth Services Review, 26, 1141-1154.

Featherstone, B., White, S. and Morris, K. 2014. Re-imagining Child Protection: Towards Humane Social Work with Families. Policy Press, Bristol.

Freeman, R. 1999. Recursive politics: Prevention, modernity and social systems. Children and Society, 13, 232-241.

Gilbert, N., Parton, N. and Skivenes, M. 2011. Child Protection Systems: International Trends and Orientations. Oxford University Press, UK.

Gupta, A. and Blewett, J. 2007. Change for Children? The challenges and opportunities for the children's social work workforce. Child and Family Social Work, 12, 2, 172-181.

Hayden, C. and Jenkins, C. 2014. "Troubled families" programme in England: "Wicked problems" and policybased evidence. Policy Studies, 35, 6, 631-649.

Howe, D. (1996) Surface and depth in social work practice. In Parton, N. (Ed.) Social Theory, Social Change and Social Work. Routledge, London, pp. 77-97.

Lascoumes, P. and Le Gales, P. 2007. Introduction: Understanding public policy through its instruments from the nature of instruments to the sociology of public policy instrumentation. Governance: An International Journal of Policy, Administration, and Institutions, 20, 1, 1-21. 
Le Gales, P. 2011. Policy Instruments and Governance. In Bevir, M. (Ed.) The SAGE Handbook of Governance, ch. 20, pp. 142-160.

Lonne, B., Parton, N., Thomson, J. and Harries, M. 2009. Reforming Child Protection. Routledge, London.

Munro, E. 2004. The impact of audit on social work practice. British Journal of Social Work, 34, 8, 1075-1095.

Munro, E. 2010. Learning to reduce risk in child protection. British Journal of Social Work, 40, 1135-1151.

Munro, E. 2011. The Munro Review of Child Protection: Final Report - A child-centred system. Department for Education, London.

Packman, J., Randall, J. and Jacques, N. 1986. Who Needs Care? Social Work Decisions about Children. Basil Blackwell, Oxford.

Parton, N. 2006. Safeguarding Childhood: Early Intervention and Surveillance in a Late Modern Society. Palgrave Macmillan, Basingstoke.

Power, M. 2004. Counting, control and calculation: Reflections on measuring and management. Human Relations, 57, 6, 765-783.

QCPCI - Queensland Child Protection Commission of Inquiry. 2013. Taking Responsibility: A Roadmap for Queensland Child Protection. Brisbane, Author.

Salamon, L.M. 2002. The tools of government: A guide to the new governance. Oxford University Press, Oxford.

SCRGSP (Steering Committee for the Review of Government Service Provision). 2015. Report on Government Services 2015, Productivity Commission, Canberra.

Testa, M.F. and Poertner, J, eds. 2010. Fostering Accountability: Using Evidence to Guide and Improve Child Welfare Policy. Oxford University Press, New York.

Thoburn, J. 2013. Troubled families, troublesome families, and the trouble with Payment by Results. Families, Relationships and Societies, 2, 3, 471-475.

Tilbury, C. 2004. The influence of performance measurement on child welfare, British Journal of Social Work, $34,2,225-241$.

Tilbury, C. and Thoburn, J. 2008. Children in out-of-home care in Australia: international comparisons. Children Australia, 33, 3, 5-12

Tomison, A.M. 2002. Preventing child abuse: changes to family support in the 21st century. Child Abuse Prevention Issues, 17, 1-22.

valentine, k. 2015. Complex Needs and Wicked Problems: How Social Disadvantage Became Multiple. Social Policy and Society, Advance online DOI: 10.1017/S1474746415000342

Van Nijnatten, C, Hopman, M, and Knijn, T. 2014. Child Protection Victims and the "Evil Institutions". Social Sciences, 3, 4: 726-741.

Ward, H. and Skuse, T. 2001. Performance targets and stability of placements for children long looked after away from home. Children and Society, 15, 5, 333-346.

Legislation

CPA 1999 Child Protection Act 1999 (QId) 